\title{
Physiological variability in CSF motion using magnetic resonance time spatial labeling inversion pulse (Time-SLIP) - real time imaging
}

\author{
Shinya Yamada
}

From Hydrocephalus 2015

Banff, Canada. 18-21 September 2015

\section{Introduction}

The ideal tracer for studying CSF dynamics is CSF itself. In time spatial labeling inversion pulse (Time-SLIP), MR radiofrequency pulses convert specific volumes of CSF into an endogenous tracer. CSF dynamics can then be observed under physiological and pathophysiological conditions. A gate-free and fast image acquisition technique like Time-SLIP is necessary to visualize natural CSF motion, whose behavior varies with cardiac pulsation and respiration.

\section{Aim}

To study physiological variability in CSF motion using the MRI Time-SILP method.

\section{Methods}

A real-time Time-SLIP balanced steady state free precession (bSSFP) sequence was used on $1.5 \mathrm{~T}$ and $3 \mathrm{~T}$ MRI scanners. Acquisition time for each image was approximately $130 \mathrm{msec}$. Serial images were obtained one to five seconds after the labeling pulse. Pulsatile CSF motions over four to five cardiac strokes were analyzed.

\section{Result}

Considerable pulsatile CSF motion variability was observed in normal physiological brains as well as pathophysiological (hydrocephalus) brains.

\section{Conclusion}

Real-time MR imaging is necessary to investigate natural pulsatile CSF motion. Averaging over multiple pulsatile

Correspondence: shinyakoro@gmail.com

Toshiba Rinkan Hospital, Japan
CSF motions potentially wipes out natural physiological variability in CSF motion.

Published: 18 September 2015

Reference

1. Yamada S, Tsuchiya K, Bradley WG, Law M, Winkler ML, Borzage MT Miyazaki M, Kelly EJ, McComb JG: Current and Emerging MR Imaging Techniques for the Diagnosis and Management of CSF Flow Disorders: A Review of Phase-Contrast and Time-Spatial Labeling Inversion Pulse. AJNR Am J Neuroradiol 2014.

doi:10.1186/2045-8118-12-S1-O27

Cite this article as: Yamada: Physiological variability in CSF motion using magnetic resonance time spatial labeling inversion pulse (Time-SLIP) real time imaging. Fluids and Barriers of the CNS 2015 12(Suppl 1):O27.
Submit your next manuscript to BioMed Central and take full advantage of:

- Convenient online submission

- Thorough peer review

- No space constraints or color figure charges

- Immediate publication on acceptance

- Inclusion in PubMed, CAS, Scopus and Google Scholar

- Research which is freely available for redistribution 